\title{
Association of testosterone levels with socio-demographic characteristics in a sample of Ugandan men
}

\author{
Miriam Nansunga ${ }^{1}$, Yukari C. Manabe ${ }^{2,3}$, Paul E. Alele *4, Josephine Kasolo ${ }^{5}$
}

1. Department of Physiology, Kampala International University, Ishaka Campus. P.O. Box 71, Bushenyi, Uganda.

Email: mnansunga@,yahoo.com

2. Division of Infectious Diseases, Department of Medicine, John Hopkins University, Baltimore, Maryland, USA

3. Infectious Diseases Institute, Makerere College of Health Sciences, P.O. Box 22418, Kampala, Uganda

Email: ymanabe@jhmi.edu

4. Department of Pharmacology, Mbarara University of Science and Technology, P.O. Box 1410, Mbarara, Uganda

Email: paulalele@must.ac.ug.

5. Department of Physiology, Makerere College of Health Sciences, P.O. Box 7072, Kampala, Uganda

Email: jkasolo@,chs.mak.ac.ugKampala, Uganda

\begin{abstract}
Background: Testosterone, a male reproductive hormone, affects several physiological processes, such as sperm production, energy, strength, sexual behavior, sleep and the general well being of men. Normal levels of testosterone are necessary to effect these physiological processes. The objective of this study was to study the association between testosterone levels in a sample of Ugandan men with socio-demographic characteristics, and compare the testosterone levels of Ugandan men with that of men in other countries.

Methods: Eighty men were enrolled from the medical campus at Makerere University. Blood samples were drawn from $7.00-8.00 \mathrm{a} . \mathrm{m}$. and total testosterone was measured using radioimmunoassay. The free and bioavailable testosterone was calculated after measuring sex hormone binding globulin (SHBG) and albumin in the blood samples. Self-administered questionnaires were used to obtain socio-demographic characteristics of the subjects. Biometric measurements including weight, height and waist circumference were also recorded.

Results: Serum testosterone levels of Ugandan men were within the normal physiological ranges. Married participants and those with dependents had lower testosterone than unmarried participants and those without dependents respectively. Sexually active participants had lower testosterone levels than those who were not sexually active.

Conclusion: Testosterone levels were lower in association with several socio-demographic characteristics including being married, having dependents, and daily coital frequency. Further research is warranted into the relationship between testosterone levels and contributory sexual behavior that may be important in understanding the spread of HIV/AIDS, given its high prevalence in sub-Saharan Africa.
\end{abstract}

Key Words: Testosterone, Socio-demographic Factors, Ugandan Men

African Health Sciences 2014; 14(2):348-355

DOI: http://dx.doi.org/10.4314/ahs.v14i2.9

\section{Introduction}

Testosterone is a male reproductive hormone produced by the Leydig cells of the testes. It occurs in both males and females, and is the most abundant androgen in men. Normal physiological levels of testosterone are essential for sperm production and are essential to

\section{*Corresponding author: \\ Paul E. Alele \\ P.O. Box 1410, Mbarara, Uganda \\ Phone: +256773573372 \\ Email: paulalele@must.ac.ug}

maintain muscle mass, strength, libido, sexual performance, and rates of metabolism ${ }^{1}$. In Western men, the normal levels of total serum testosterone range from 12.5 - $30.5 \mathrm{nmol} / \mathrm{L} .{ }^{2}$ Data available for Western men in the 40-60 year age group, show that total serum testosterone levels range from $8.7-31.7 \mathrm{nmol} / \mathrm{L}$ for men in their $40 \mathrm{~s}$, to $7.4-30.3 \mathrm{nmol} / \mathrm{L}$ for men in their $50 \mathrm{~s}$, and 6.8 - 29.8 for men in their 60s. ${ }^{3}$ Data from sub-Saharan Africa, in South Africa, have shown normal testosterone levels of $14.6 \pm 4.9$ for healthy, ambulant white men aged 20 - 49 years, with normal sperm counts; these mean total testosterone levels were in the lower range of normal ${ }^{4}$. In 40 healthy black fathers aged 30 - 39 years, also with normal sperm counts, the mean 
total testosterone levels were slightly higher, but still in the lower range $(16.9 \pm 4.7 \mathrm{nmol} / \mathrm{l})$, while healthy men aged 40 - 49 had their mean total testosterone levels reduced to $11.4 \pm 5.1 \mathrm{nmol} / 1{ }^{4}$ These data suggest that healthy men in South Africa have lower total testosterone values than that of men in international studies, especially in Western countries ${ }^{4}$. Another study in South Africa examined variation in testosterone levels in men aged between 20 and 82 years across subgroups of an urbanization gradient that represented differences in both geography and socioeconomic status. ${ }^{5}$ This South African study, called the Transition and Health During Urbanization of South Africans (THUSA) study, found that male testosterone levels differed significantly among the urban and the rural groups. Men in the most urban group had higher testosterone levels than among groups of farmers and men in informal housing rural areas. ${ }^{5}$ Further, this study showed an age-related decline in testosterone levels. ${ }^{5}$

The age-related decline of testosterone is highly variable and depends on many factors. ${ }^{6}$ This age-related decline has been reported in Western populations, ${ }^{7,8,9}$ and has also been reported in other populations in resource-limited settings including Pakistan, Kenya, Zimbabwe, Democratic Republic of Congo, and, Nepal. Gray and colleagues reported a downward trend, although not prominent, in salivary testosterone levels with age for Kenyan Ariaal men who have a subsistence livelihood. ${ }^{10}$ Similar findings have also been reported in Zimbabwean men ${ }^{11}$, American men, ${ }^{7,8,12}$ and Japanese men. ${ }^{13}$

Testosterone levels can differ among different ethnic groups; Pakistani men have lower testosterone levels than men from Europe, Africa, and the Caribbean. ${ }^{14,15}$ Ross reported that there was a statistically significant $(21 \%)$ difference in the free testosterone among black college students compared to their white counterparts. ${ }^{16}$ Uganda's population comprises diverse ethnic groups with varying customs and norms. The 2002 census classified Ugandans into the 56 legally recognized ethnic groups at the time. ${ }^{17}$ There could be previously unrecognized tribe-to-tribe variability in testosterone levels. Low testosterone levels have been associated with, stress, injury, chronic diseases like diabetes, hypertension and cancer. ${ }^{6,18}$ Symptoms associated with low testosterone levels include depression, fatigue, irritability, reduced libido, body pains, and decreased sexual performance. ${ }^{19}$

Animal studies have shown a strong link between high levels of testosterone and aggressive behavior; ${ }^{20}$ intramuscular injection of testosterone propionate in cynomolgus monkeys increased the frequency of aggressive behaviour in these monkeys. However, aggressive behaviour was mediated by social status i.e. incidence of both contact and non-contact aggression in dominant monkeys was far greater than frequency of these behaviour in subordinate monkeys. ${ }^{20} \mathrm{In}$ general, studies suggest that androgens modulate neural pathways of social behavior such as the expression of aggressive and sexual behavior in male vertebrates, but this expression is dependent on the social context. ${ }^{21}$

High testosterone levels are also associated with prostate cancer. African-Americans in the United States have the highest rate of prostate cancer in the world, ${ }^{12,22}$ a finding that may be linked to the high free testosterone levels in these men. The main objective of our study therefore, was to describe the relationship between testosterone levels found in a sample of Ugandan men and their socio-demographic characteristics, and to compare the testosterone levels of Ugandan men with levels in men of similar ages in studies reported from other countries.

\section{Methods \\ Study Population}

Study participants were healthy Ugandan men on the Makerere University Medical campus. Students and both academic and non-academic staff were enrolled in the study. Representative participants from the major regions of the country were recruited to cater for the diverse ethnic groups. The participant's ages were between 18 and 60 years.

\section{Sampling Procedure}

Written and oral advertisements were made, requesting for volunteers. Participants reported to the department of Physiology between 7.00 and 8.00 a.m. daily, and provided written informed consent. Sampling was consecutive provided the volunteer was within the target population.

\section{Data collection}

Qualified technicians and trained research assistants collected the data. The height, weight and waist circumference of participants were measured and body mass index (BMI) was calculated in $\mathrm{Kg} / \mathrm{m}^{2}$. Only participants with BMI less than $30 \mathrm{~kg} / \mathrm{m}^{2}$ were included in the study. The participants then filled a self-administered questionnaire. Trained laboratory technicians drew the blood from the antecubital veins of participants. The blood was placed in separate 
vacutainers and allowed to stand for five hours, after which the serum was harvested and stored at $-20^{\circ} \mathrm{C}$.

\section{Laboratory procedure}

Testosterone radioimmunoassay (RIA ) kit (Institute of Isotopes Co. Ltd. Budapest, Hungary) was used to measure total testosterone levels. Albumin and sex hormone binding globulins (SHBG) were also measured and free testosterone was calculated according to previously published methods. ${ }^{5}$ These tests were carried out at the Nuclear Medicine Laboratory at Makerere University whose RIA lab is housed in the Physiology Laboratory. The RIA Laboratory has been upgraded and accredited by the International Atomic Energy Agency (IAEA), and undergoes annual license renewals and regular inspections.

\section{Data management and analysis}

Data was entered into a computer using EpiInfo ${ }^{\circledR}$ and exported to SPSS ${ }^{\circledR}$

Version 11 for analysis. Data was double-entered and verified for accuracy. Descriptive numerical summaries of the continuous variables were obtained then statistical analyses done using multiple regression analysis. The dependent variables were serum total testosterone, free testosterone, and bioavailable testosterone. Tests of significance were done using the F-test and significant association of testosterone (total, free, or bioavailable) with the demographic characteristics shown for $\mathrm{p}<$ 0.05 .

\section{Ethical considerations}

Participants gave written informed consent before they were enrolled in the study. The study was reviewed and approved by the Institutional Review Board of Makerere University Medical School. Trained laboratory technologists took the samples.

\section{Results}

Eighty men provided informed consent and had their biometric factors and plasma testosterone levels measured. Fifty-two of the respondents were married $(65 \%)$ while sixty-one $(76 \%)$ had dependents. Marital status was defined as a respondent who was customarily married, religiously wedded, or married by civil union, or was cohabiting with their spouse(s). We did not differentiate between monogamous and polygamous marriages, since the sample size was small. For the unmarried men we assumed that those who did not have sexual partners were those who reported not being sexually active for our question of coital frequency in a week. Many of the unmarried men reported being sexually active. Dependents were considered in the questionnaire as all children aged 8 years and below, both biological and non-biological, who were cared for, or provided for, and lived with the respondent.

Table 1 summarizes the results for biometric measurements including body weight, height, body mass index (BMI), and waist circumference; testosterone (total, bioavailable and free), and testosterone binding proteins (albumin and sex hormone binding globulin, SHBG). All the biometric measurements were within the normal physiological ranges. The testosterone levels and testosterone binding proteins for the respondents also were within the normal physiological ranges for each variable studied.

Table 1. Biometric measurements and results for albumin and SHBG, and total, bioavailable and free testosterone

\begin{tabular}{|l|l|}
\hline Variable & Mean \pm SD \\
\hline Weight & $61.0 \pm 8.1 \mathrm{~kg}$ \\
Height & $1.7 \pm 0.05 \mathrm{~m}$ \\
BMI & $20.7 \pm 28 \mathrm{~kg} / \mathrm{m}^{2}$ \\
Waist circumference & $31.9 \pm 2.7 \mathrm{~cm}$ \\
SHBG & $51.0 \pm 35.9 \mathrm{nmol} / 1$ \\
Albumin & $44.0 \pm 4.2 \mathrm{nmol} / 1$ \\
Total testosterone & $22.3 \pm 5.7 \mathrm{nmol} / 1$ \\
Free testosterone & $0.5 \pm 0.4 \mathrm{nmol} / 1$ \\
Bioavailable testosterone & $11.1 \pm 4.2 \mathrm{nmol} / 1$ \\
& \\
\hline
\end{tabular}

Data are shown as means \pm standard deviations of participants' biometric and laboratory values. All the parameters measured were within the normal physiological ranges.

There was no statistically significant difference between total serum testosterone, bioavailable testosterone, or free testosterone levels across age strata (Table 2). The majority of the respondents $(30 \%)$ reported having sex once a week; $24 \%$ reported having sex daily and $12 \%$ reported not being sexually active. Participants who reported having sex daily had the lowest bioavailable 
testosterone (BT) value of $8.4 \pm 4.4 \mathrm{nmol} / \mathrm{l} ; \mathrm{p}=0.018$ compared to those who reported not being sexually active with the highest BT value of 15.5 5.5 (Table 3). In this model, as depicted in Table 2, the majority of men in the youngest group studied (18-27) were single compared to the rest of the older groups. Contrariwise, the majority of men in the oldest group (48+) were married, compared to the youngest group (18-27). Furthermore, while the youngest group had similar numbers of men with and without dependents, the majority of men in the older groups had dependents.

Table 2: Frequency, marital status, presence of dependents, and mean with $95 \% \mathrm{CI}$ of total, bioavailable, and free testosterone for different age strata

\begin{tabular}{|l|l|l|l|l|l|l|l|l|}
\hline $\begin{array}{l}\text { Age } \\
\text { strata }\end{array}$ & $\begin{array}{l}\text { Freq. } \\
(\mathrm{n})\end{array}$ & Married & Single & $\begin{array}{l}\text { Had } \\
\text { dependents }\end{array}$ & $\begin{array}{l}\text { Had no } \\
\text { dependents }\end{array}$ & $\begin{array}{l}\text { Mean total } \\
\text { testosterone } \\
\text { (nmol/L) }\end{array}$ & $\begin{array}{l}\text { Mean } \\
\text { bioavailable } \\
\text { testosterone } \\
\text { (nmol/L) }\end{array}$ & $\begin{array}{l}\text { Mean free } \\
\text { testosterone } \\
(\mathrm{nmol} / \mathrm{L})\end{array}$ \\
\hline $18-27$ & 22 & 5 & 17 & 10 & 12 & $24.0(20.8-27.2)$ & $13.4(10.0-16.8)$ & $0.5(0.4-0.6)$ \\
$28-37$ & 21 & 17 & 4 & 18 & 3 & $23.4(19.9-26.9)$ & $9.7(7.5-11.8)$ & $0.4(0.3-0.5)$ \\
$38-47$ & 19 & 15 & 4 & 16 & 3 & $20.8(17.2-24.4)$ & $11.0(7.2-14.8)$ & $0.4(0.3-0.6)$ \\
$48+$ & 18 & 15 & 3 & 17 & 1 & $21.6(17.1-26.2)$ & $10.1(6.6-13.7)$ & $0.5(0.3-0.6)$ \\
\hline
\end{tabular}

The majority of men in the youngest group studied (18-27) were single compared to the rest of the older groups. Contrariwise, the majority of men in the oldest group $(48+)$ were married, compared to the youngest group (18-27). Furthermore, while the youngest group had similar numbers of men with and without dependents, the majority of men in the older groups had dependents; further statistical testing was limited because of the sample sizes. There were no statistically significant differences in the mean total testosterone levels, mean bioavailable testosterone, and mean free testosterone levels for the different age strata.

The mean BT for married participants was much lower $\mathrm{p}=0.027$, than those who were single (Table 3 ); similarly, participants who reported having dependents had much lower BT ( $\mathrm{p}=0.005)$ compared to those who did not have dependents (Table 3).

Men who reported daily coitus had the lowest bioavailable testosterone compared to those who reported no sexual activity $\left({ }^{a} \mathrm{p}=0.018\right)$. There was a statistically significant reduction in bioavailable testosterone in married men compared to single men $\left({ }^{*} \mathrm{p}=0.024\right)$. Seven of 22 men in the 18-27 age group reported not being sexually active (the highest number of respondents) with five single men in this age group; two of 21 men in the 2837 age group reported not being sexually active, with four men in this age group being single. There was also a statistically significant reduction in bioavailable testosterone in men with dependents compared to men without dependents $\left({ }^{* *} \mathrm{p}=0.005\right)$. 
Table 3: The relationship between bioavailable testosterone and region of origin, coital frequency, marital status, and dependents

\begin{tabular}{|l|l|}
\hline Variable & $\begin{array}{l}\text { Bioavailable testosterone } \\
\text { Mean } \mathbf{( 9 5 \%} \mathbf{C I}) \mathbf{S D} \text { nmol } / \mathbf{1}\end{array}$ \\
\hline Region of origin & $9.6 \pm 5.6$ \\
\hline Eastern & $10.7 \pm 4.3$ \\
\hline Northern & $13.8 \pm 8.7$ \\
\hline Southern & $10.6 \pm 6.7$ \\
\hline Western & ${ }^{2} 8.4 \pm 4.4$ \\
\hline Coital frequency & $9.7+4.0$ \\
\hline Daily & $14.0 \pm 9.6$ \\
\hline Twice a week & $12.4 \pm 8.5$ \\
\hline Three times a week & $15.1 \pm 5.5$ \\
\hline Once a week & $14.7 \pm 7.9$ \\
\hline Not sexually active & $13.5 \pm 4.5$ \\
\hline Marital status & \\
\hline Married & \\
\hline Single & \\
\hline Dependents & \\
\hline Have dependents & \\
\hline No dependents & \\
\hline
\end{tabular}

\section{Discussion}

The serum testosterone levels of Ugandan men fall within the normal physiological ranges, which are quite wide. However, the Ugandan levels are higher for all age groups compared to the normal levels described in other sub-Saharan and other Western studies, ${ }^{2-5,8,9}$ with the biggest difference being observed in the oldest age group. The findings of our study are consistent with those obtained in previous studies done in the Western world ${ }^{7-9,12,15}$ probably because the participants had normal BMI and waist circumference and were healthy. It could also be that the Ugandan men naturally have relatively higher levels.

The findings in this study are consistent with earlier studies that reported that all forms of testosterone tend to decrease with age $\mathrm{e}^{7-9,15}$. The downward trend of testosterone is mainly due to the physiological changes in the hypothalamus-pituitary-testis axis (HPT) with age. Aging is associated with changes both within the testes and at the level of the pituitary and hypothalamus. Leydig cell number decreases while serum LH levels rise. Several changes in the neuroendocrine pathway controlling testosterone production in healthy older men are consistent with the degree of secondary testicular failure including amplitude to endogenous LH pulse ${ }^{23}$. There may also be altered feedback control of individual and coupled GnRH-LH secretory activity gonadal signal ${ }^{15}$. Furthermore, there may be disruption of effective (LH-T) stimulus-secretion coupling at the level of Leydig cells in the testis.

Some earlier studies have reported older men having relatively high salivary testosterone levels compared to younger men. ${ }^{6,13}$ Our study had several interesting differences with other studies. First, we did 
not show that free testosterone decreased with age ${ }^{25,26}$ This difference could be due to the nature of our study since only one sample was taken from each individual, and there is sufficient intraindividual variability over weeks and months to at least warrant two samples. ${ }^{27}$ It could also be that the younger participants had unexpectedly low testosterone for reasons speculated on above. We also found that the mean values for both free testosterone $(0.5 \mathrm{nmol} / \mathrm{L})$ and bioavailable testosterone $(11.1 \mathrm{nmol} / \mathrm{L})$ obtained from the present study, are higher than the other mentioned studies. ${ }^{28-30}$ This could be due to factors including normal BMI and waist circumference, as all the participants were nonobese and non-smokers and this could have contributed to having normal levels of testosterone.

Remarkably, when separated into age strata, our Ugandan male cohort had testosterone levels that were consistently on the higher end of the normal physiologic ranges. A potential reason for this could be ethnicity or diet ${ }^{14}$. The findings from this study concur with earlier reports, which suggest that there may be ethnic variations in testosterone levels. Within Uganda, however, testosterone levels showed small, nonsignificant variations compared to population variations seen elsewhere. ${ }^{11,16}$ Further investigations into genetic or dietary factors are needed.

The findings from this study revealed that the married men had statistically significant, lower bioavailable testosterone than the unmarried $(\mathrm{p}=0.027)$, which is consistent with earlier findings. ${ }^{24}$ Furthermore, our study revealed that the men who had dependents/ children also had lower testosterone, compared to those without dependents, and the difference was statistically significant $(p=0.005)$. This also agrees with earlier studies ${ }^{14,25}$ that reported low testosterone among married men and fathers. Our findings in the sample of Ugandan men studied also showed that the majority of men in the youngest group (18-27) were single compared to the rest of the older groups; contrariwise, the majority of men in the oldest group (48+) were married, compared to the youngest group (18-27), and, while the youngest group had similar numbers of men with and without dependents, the majority of men in the older groups had dependents. These predictable findings could potentially be because of age-related shifts in male roles and relationships, as well as challenges of completing school and employment experienced by younger men at the study setting (medical campus), that make it less appealing to marry or have dependents at their ages, compared to the well-established older men. The higher testosterone levels among the unmarried men and without dependents could be due to male-male competition during finding mates ${ }^{21}$. Our findings also add to the body of evidence that marriage and parenting may be potentially important factors influencing male testosterone variation.

Contrary to the general belief that individuals with low libido have lower testosterone levels, participants who reported having sex daily had the lowest levels of BT, while those who reported not being active sexually had the highest BT levels. This may be related to the difference in marital status, where married men, due to close proximity or demand by their women, had higher coital frequency than the unmarried men. It is well-recognized that married individuals tend to have more frequent sexual behavior than unmarried individuals, even if the extent of that difference varies by country and other contextual factors. ${ }^{31}$ Our finding (of higher testosterone levels in less sexually active men) was in agreement with earlier findings, which reported that the mean testosterone levels were higher for less sexually active individuals ${ }^{32}$. However, we did not obtain evidence of the living circumstances of the single men, whether they lived alone on their own, or lived at home with their parents, a fact that could contextualize the single men's' higher testosterone levels.

Our study had several other limitations. The number of participants in each age group was small. We depended on self-reporting about the presence of chronic diseases; hence, the participants may not have been very honest about their sexual behavior, including whether or not they had partners, since we did not get evidence of their marital status. Additionally, the study was cross-sectional, and we did not follow up to see how the levels of testosterone and its fractions changed in one individual. The difference could be due to the nature of the study since only one sample was taken per individual.

\section{Conclusion}

The serum testosterone levels of the sample of Ugandan men studied fall within the normal physiological range, although the levels are higher than most of those reported by other studies for particular age groups. Married men had lower bioavailable testosterone levels than single men. Similarly, men who had dependents had lower bioavailable testosterone than men who did not have dependents. Men who reported having sex daily had considerably lower testosterone than men who reported not being sexually active. There may be testosterone differences that contribute to related sexual behavior, especially aggressive sexual behavior such as rape that 
may be important in understanding the spread of HIV/ AIDS. Therefore, further research into the association between testosterone levels, particularly bioavailable testosterone and behavior is warranted, given the high prevalence of sexually transmitted disease such as HIV in sub-Saharan Africa.

\section{Competing interests}

The authors declare that they have no competing interests.

\section{Authors' contributions}

MN conceived the study and carried out data collection; $\mathrm{MN}$ and $\mathrm{JK}$ contributed to the study design and data analysis; MN wrote the first draft; and PEA and YCM contributed to the manuscript writing. All authors contributed to the manuscript, read and approved the final submitted version.

\section{Acknowledgement}

The authors gratefully acknowledge the assistance given by MEPI-MESAU.

This work was supported by Grant Number 5R24TW008886, supported by OGAH. NIH and HRSA. Its contents are solely the responsibility of the authors and do not necessarily represent the official views of the supporting offices

\section{References}

1. Nieschlag E., Swerdloff R., Behre H.M., et al. Investigation, treatment and

monitoring of late-onset hypogonadism in males. ISA, ISSAM, and EAU

recommendations. Eur Urol 2005; 48: 1-4.

2. Thijssen JHH. Laboratory tests in the endocrine evaluation of aging males. In: Lunenfeld B, Goosen L, eds. Textbook of Men's Health. London: Parthenon Publishing Group, 2002: 44-50.

3. Mohr BA, Guay AT, O’Donnell AB, Mckinlay JB. Normal, bound and non-bound testosterone levels in normally aging men: results from the Massachusetts Male Aging study. Clinical Endocrinol (Oxf); 2005; 62(1): 64-73.

4. Bornman MS, Roux M, Vermaak W, Reif S. Serum testosterone levels in proven fertile, normozoospermic men: a better group for 'normal' values? Aging Male 2000; 3: suppl 1, 87.

5. Gray P.B., Kruger A, Huisman H.W., Wissing M.P.,
Vorster H.H. Predictors of South African male testosterone levels: the THUSA study. American Journal of Human Biology, 2006;18 (1): 123-132.

6. Isidori A.M., Lenzi A. Risk factors for androgen decline in older males, lifestyle, chronic disease and drugs; 2006.

7. Ferrini, R.L., Barrett-Connor. Sex hormones and age a cross-sectional Study of testosterone and estradiol and their bioavailable fractions in community-dwelling men. American Journal of Epidemiology ; 1998 147, 750-54.

8. Vermeulen A., Goemaere S., Kaufman J.M. Testosterone, body composition and aging. Journal of Endocrinological Investigations 1999, 22 Suppl. 5 110-116.

9. Harman S.M., Metter E.J., Tobin J.D., Pearson J., Blackman M.R. Longitudinal effects of aging on serum total and free testosterone levels in healthy men. Journal of Clinical Endocrinology and Metabolism. 2001 86:724-731. 10. Gray P.B., Ellison P.T., and Campbell B.C. Testosterone and marriage among Ariaal men of northern Kenya. Current Anthropology 2007, 48: 750-755.

11. Lukas W.D., Campbell B.C., Ellison P.T. Testosterone, aging and body composition in men from Harare, Zimbabwe. American Journal of Human Biology; 2004 16:704-712

12. Ross R., Bernstein L., Judd H., Hanisch R., Pike M., Henderson B. Serum testosterone levels in healthy, young black and white men. J National Cancer Institute 1986; 76(1): 45-48.

13. Akiko U., Bribiescas R.G., Travison P.P. et al. Age-related variation of salivary testosterone values in healthy Japanese males. Aging Male; 2006. (4): 207-13

14. Heald A.M., Ivison F., Anderson S.G., Cruickshank K., Laing I., Gibson J.M. Significant ethnic variation in total and free testosterone. Clinical Endocrinology $(O x f)$. 2003 59(3):262-6.

15. Majon M., den Tonkelaar T., Thijssen J.H., Grobbee D.E., Schouw V.der Y.T. Endogenous sex hormones in men aged 40-80 years. European Journal of Endocrinology; $2003149583-589$.

16. Ellison P.T., Bribiescas R.G., Bentley G.R. et al. Population variation in age-related decline in male salivary testosterone. Human Reproduction 2002.17 (12): 32513253.

17. Mukasa J.B.M. The 2002 Population and Housing Census. 2002

18. Svartberg J., Muhler D. v., Schirmer H., Connor E.B., Sundjord J., Jorde R.. Association of endogenous testosterone with blood pressure and left ventricular mass in men. European Journal of Endocrinology 2004150 65-71. 19. Jed Diamond. 1997; Male Menopause. Source- 
books, Inc, Naperville.

20. Rejeski W.J., Brubaker P.H., Herb R.A., Kaplan J.R. \& Koritnik D.J. Anabolic steroids and aggressive behaviour in cynomolgus monkeys. Behavioral Medicine; 1988, 11; 95-105.

21. Oliveira R.F. Social behavior in context: Hormonal modulation of behavioral plasticity and social competence. Integrative and Comparative Biology, 2009; 49 (4): 423-440.

22. Kubricht W.S., Willias B.J., Whatley T., Pinckard P., Eastham J.A. Serum testosterone levels in AfricanAmerican and white men undergoing prostate biopsy. Urology;1999, 54 (6):1035-8.

23. Veldhius J.D., Iranmanesh A., Godschalk M. and Mulligan T. Older men manifest multifold synchrony disruption of reproductive neurohormone outflow. The Journal of Clinical Endocrinology and Metabolism; 2000, 88 (4) 1477- 1486.

24. Gray P.B., Kahlenberg S.M., Barrett E.S., Lipson S.F., Ellison P.T. Marriage and fatherhood are associated with lower testosterone in males. Evolution of $\mathrm{Hu}$ man Behavior. 193-201.

25. Travison T.G., Morley J.E., Araujo A.B., O’Donnell A.B., Mckinlay J.B. The relationship between libido and testosterone levels in aging men. Clinical Endocrinology and Metabolism; 2006. 9 (7): 2509-13.

26. Gupstur S.M., Kopp P., Gann P.H., Chiu B.C., Colangelo L.A., Liuk. Changes in BMI modulate age-associated changes in sex hormone binding globulin and total testosterone but bioavailable testosterone in young adult men. Int J Obesity (London) 2007; 31 (4) 685-91.

27. Andersson A.-M., Cailsen E., Petersen J.H. and Stakkebek N.E. Variations in levels of serum inhibin $\mathrm{B}$, testosterone, estradiol, luteinizing hormone, follicle stimulating hormone, and sex hormone binding globulin, in monthly samples from healthy men during a 17month period: possible effects of seasons. The Journal of Clinical Endocrinology \& Metabolism;2003.88 932-937

28. Ronde W.d, Yvone T., Schouw V.d, Muller M., Grobbee D.E., Louis J.G. Goorey, Huibert A.P. Sex-hormone binding globulin (SHBG) with non-SHBG-bound levels of testosterone and estradiol in independently living men. Journal of Clinical Endocrinology \& Metabolism; 2005 90(1):157-162.

29. Ho C.K., Stoddart M, Walton, Aderson R.A., Beckett G.J. Calculated free testosterone in men: comparison of four equations and free androgen index. Ann Clinical Biochemistry; 2006; 43(5) 389-97.

30. Rosner W., Anchus R.J., Azziz R., Sluss P.M. and Raff H.. Utility, limitation and pitfalls in measuring testosterone: An Endocrine Society position statement. Journal of clinical Endocrinology and Metabolism 200792 (2): 405-413.

31. Wellings K., Collumbien M., Slaymaker E., Singh S., Hodges Z., Patel D., Bajos N. Sexual behaviour in context: a global perspective. Lancet. 2006; 368(9548):170628.

32. Kraemer H.C., Becker H.B., Brodie M.D et al. Orgasmic frequency and plasma testosterone levels in normal human males. Sexual Behaviour. 1976.5 (2): 125132. 